\title{
CURRENT APPROACHES IN DIAGNOSIS AND TREATMENT OF PATIENTS WITH PERITONITIS
}

\author{
E. Enchev $^{1 *}$, A. Muman ${ }^{1}$, G. Minkov ${ }^{1}$, E. Dimitrov ${ }^{1}$, A. Petrov ${ }^{2}$, St. Nikolov ${ }^{1}$, \\ Y. Yovtchev ${ }^{1}$
}

\author{
${ }^{1}$ Department of Surgical Diseases and Anaesthesiology, Trakia University, Stara Zagora, Bulgaria \\ ${ }^{2}$ Department of General Surgery, Neurosurgery and Urology, Faculty of Medicine, Trakia University, \\ Stara Zagora, Bulgaria
}

\begin{abstract}
Background: Intra-abdominal infections (IAIs) are a wide range of pathological conditions that affect all intra-abdominal tissues and organs. These include both inflammation of individual organs and any type of peritonitis (primary, secondary, tertiary), where the severity of the disease often depends on the spread of inflammation - local or diffuse peritonitis.

Methods: In this article,we present a review and analysis of current definitions, classifications, and approaches in the diagnosis and treatment of intra-abdominal infections.

Results and Conclusions: IAIs remain an important cause of morbidity and mortality in modern surgical practice worldwide. Early and accurate clinical diagnosis, adequate local control, appropriate antimicrobial therapy according to the patient's risk factors and infection, and prompt resuscitation in critically ill patients are the cornerstones of IAI management. The application of the principles of evidence-based medicine and the individual approach to patients is crucial for optimizing results.
\end{abstract}

Key words: Intra-abdominal infection, approaches, peritonitis

\section{INTRODUCTION}

Intra-abdominal infection (IAI) is one of the most common causes of hospitalization. Although community-acquired IAIs are associated with low mortality, hospitalacquired IAIs have significant morbidity and mortality in the critically ill patients and at the same time require significant financial and human resources in the hospital. IAIs represent a wide range of pathological conditions. The aim of the present study is to analyze current definitions, classifications and approaches in the diagnosis and treatment of IAIs.

\section{DISCUSSION}

The term "intra-abdominal infections" includes a wide range of clinical conditions. The anatomical extent of the infection, the suspected pathogens, the risk factors for the underlying resistance patterns and the patient's clinical condition must be assessed independently to classify the patients. (World

\footnotetext{
*Correspondence to: Emil Enchev, e-mail emil.enchev@trakia-uni.bg, phone:
} +359894845263
Society of Emergency Surgery (WSES) consensus, Dublin, Ireland, 2016)

Universal classification divides IAIs into complicated - includes peritoneum - local or diffuse peritonitis and uncomplicated - affects only one organ and does not involve the peritoneum. (1)

Peritonitis essentially is an inflammation of the peritoneum, which depending on the underlying pathology can be infectious or sterile. Infectious peritonitis is divided into primary, secondary and tertiary. Primary peritonitis is a diffuse bacterial infection, usually caused by a single organism, without compromising the integrity of the gastrointestinal tract. It has a low frequency and is usually treated without surgery. Secondary peritonitis is an acute peritoneal infection resulting from a violation of the integrity of the gastrointestinal tract and is the most common. Tertiary peritonitis is a recurrent infection of the peritoneal cavity that occurs $>48$ hours after apparently successful and adequate surgical control of the source of 
secondary peritonitis. It is more common in critically ill or immunocompromised patients and can often be associated with multidrugresistant organisms. It is usually associated with high morbidity and mortality. (2-5)

\section{Diagnosis}

The diagnosis of complicated IAI is clinical. Therefore early detection and treatment are essential. (6)

The clinical picture of patients with IAI usually is present with acute abdominal pain and signs of local or systemic inflammation. Signs of hypotension and hypoperfusion are indicative for organ failure. The clinical examination is very important for diagnosis and lead to an appropriate management plan diagnostic tests, initial antimicrobial therapy and urgent surgery if required. (7)

Ultrasound and computed tomography (CT) are established methods for supplementing the clinical evaluation of patients with IAI. Although CT has higher sensitivity and specificity, there are concerns about radiation exposure. This necessitates a reassessment of the role of sonography, including that performed by surgeons. (8-10)

Magnetic resonance imaging (MRI) is not routinely used in most hospitals in an emergency. It can be used in cases of pregnant patients with abdominal pain, when the result of the ultrasound is unconvincing. (11)

Laparoscopy is increasingly used in emergency surgery with very high accuracy. Diagnostic laparoscopy is method for identification of the origin of acute abdominal pain, followed by definitive laparoscopic treatment if necessary. (12)

\section{Score systems}

High-risk IAIs are based on patient-related factors like an old age, immunosuppression, malignancy, concomitant diseases or disease factors represented by transient systems (ASA, APACHE, SOFA), delayed surgery $>24$ hours, inability for source control and hospitalacquired IAI. Patients with a large number of risk factors, including very high age and high disease severity or presented with sepsis or septic shock, have an excessively high risk of death. (13)

Prognostic systems for assessing complicated IAIs can be useful in clinical practice, especially for analysis and research.
Assessment systems can be divided into two groups: general indicators of severity of organ failure and specific peritonitis assessments. SOFA allows physicians to monitor the evolving disease process in critically ill patients in intensive care units. (14)

Disease severity assessment systems (APACHE II) or Simplified Acute Physiology Assessment (SAPS) are based on parameters during the first 24 hours of intensive care and may be applicable to patients with peritonitis. SOFA is an objective and easy assessment of severity, which allows both the calculation of the number and severity of organ dysfunction (respiratory, coagulation, liver, cardiovascular, renal and neurological systems). Specific for peritonitis (surgical) score systems - are calculated once during the operation and often include intraoperative characteristics of the degree of contamination. Surgical assessments may be disease-specific (Peritonitis Severity Score). There are also many systems for assessing perforations of gastroduodenal ulcers (Boey Score, Jabalpur Index, Hacettepe Score and PULP Score). Prognostic estimates that can be universally used in various etiologies include P-POSSUM, Mannheim Peritoneal Index (MPI), Altona Peritoneal Index (PIA). The MPI score is easy to calculate, even during operation. It is calculated using simple factors such as degree of peritonitis, age, sex, time from perforation to surgery, origin of sepsis, type of exudate (serous, purulent or feculent). $(15-17)$

\section{Treatment}

Patients with complicated IAI and sepsis or septic shock are indicated for emergency source control surgical treatment. It may be delayed in less severely ill patients when circumstances are appropriate. Source control covers all measures taken to eliminate the source of infection and to control ongoing contamination. The time and adequacy are currently the most important problems in the management. Source control should be performed as soon as possible in patients with diffuse peritonitis. In patients with localized infection this intervention may be delayed for up to 24 hours if appropriate antimicrobial therapy and active clinical monitoring are administered.

The treatment of uncomplicated IAIs is surgical and no postoperative antibiotic therapy is required.Treatment of patients with 
complicated IAI includes source control, antibiotic therapy, and potentially new therapies aimed at modulating or improving the inflammatory response. Antibiotics can prevent local and hematogenous spread and can reduce late complications.

Surgery remains the most important therapeutic strategy for controlling intraabdominal sepsis. Surgical source control includes perforation suture, resection of the affected organ or intestinal exteriorization.

A laparoscopic approach is a major tool for diagnosing and treating IAI. Based on the anatomical source of infection and the experience of the surgeon, laparoscopy may be recommended for the treatment of many IAIs. Laparoscopic lavage is a safe procedure in terms of mortality but is associated with a higher incidence of intra-abdominal abscess and reoperation. No definitive high-level conclusions can be drawn from the available literature and further evidence is needed to better determine the role of laparoscopic lavage in the treatment of IAI. (18)

The damage control surgery concept has been adopted by emergency surgeons and may be a logical continuation of pathophysiological principles in trauma to hemorrhage and sepsis as a life-saving tactic in emergency surgery applied to physiologically decompensated patients. Damage control surgery may be an option in selected patients with sepsis. (19)

Temporary abdominal closure with negative pressure (NPT) can be helpful in reducing the time to definitive abdominal closure. The aim is early and definitive closure of the abdomen to reduce complications associated with the open abdomen (entero-atmospheric fistulas, fascial retraction, massive incisional hernias) when the patient's physiological condition allows. (20)

Initial antibiotic therapy for IAI is empiric, as microbiological results require $>24$ hours. IAIs are polymicrobial infections and individual bacterial strains must first be isolated and then tested for antibiotic susceptibility. Isolation and identification of bacterial strains take longer, and antibiotic susceptibility results are usually available after 48 hours. (21)

The main pathogens involved in IAI are generally predictable and include Enterobacteriaceae (Escherichia coli and Klebsiella spp.), Streptococci and anaerobes (Bacteroides fragilis). (22) Empirical antibiotic treatment principles should be determined by the most commonly isolated microbes, always taking into account the trend of antibiotic resistance. Inadequate therapy in critically ill patients can have a strong negative impact on the outcome of the disease. Ineffective or inadequate antimicrobial regimens are one of the variables that are more strongly associated with adverse outcomes in critically ill patients. Extensive empirical antimicrobial therapy should be initiated as soon as possible in patients with organ dysfunction (sepsis) and septic shock. International guidelines for the treatment of sepsis and septic shock recommend intravenous antibiotics as soon as possible and in any case within the first hour of the onset of sepsis and the use of broad-spectrum antibiotics with adequate perfusion at the site of suspected infection. When the source of infection is effectively treated by surgery, postoperative antimicrobial therapy is not necessary. In patients with mild IAI and when control of the source is performed, a short course (3-5 days) of postoperative therapy is recommended.(23)

\section{CONCLUSION}

IAIs remain an important cause of morbidity and mortality in surgical practice worldwide. Early and accurate clinical diagnosis, timely resuscitation, adequate local control, appropriate antimicrobial therapy dictated by the patient's risk factors and infection, and prompt resuscitation in critically ill patients are the cornerstones of IAI management. The application of the principles of evidence-based medicine and the individual approach to patients is crucial for optimizing results.

\section{REFERENCES}

1. Menichetti F, Sganga G. Definition and classification of intra-abdominal infections. $J$ Chemother. 2009;21(Suppl 1):3-4. doi: 10.1179/joc.2009.21.Supplement-1.3

2. Gupta S, Kaushik R. Peritonitis - the Eastern experience. World J Emerg Surg. 2006;1:13. doi: 10.1186/1749-7922-1-13.

3. Mishra SP, Tiwary SK, Mishra M, Gupta SK. An introduction of tertiary peritonitis. $J$ Emerg Trauma Shock. 2014;7:121-3. doi: 10.4103/0974-2700.136872.

4. Reemst PH, van Goor H, Goris RJ. SIRS, MODS and tertiary peritonitis. Eur J Surg Suppl. 1996;576:47-8.

5. Lamme B, Mahler CW, van Ruler O, Gouma DJ, Reitsma JB, Boermeester MA. Clinical predictors of ongoing infection in secondary peritonitis: systematic review. World $J$ Surg. 2006;30:2170-81. doi: 10.1007/s00268005-0333-1. 
6. Solomkin JS, Mazuski JE, Bradley JS, Rodvold KA, Goldstein EJ, Baron EJ, et al. Diagnosis and management of complicated intra-abdominal infection in adults and children: guidelines by the Surgical Infection Society and the Infectious Diseases Society of America. Surg Infect (Larchmt) 2010;11:79109. doi: 10.1089/sur.2009.9930.

7. Wagner JM, McKinney WP, Carpenter JL. Does this patient have appendicitis? JAMA. 1996;276:1589-94. doi: 10.1001/jama.1996.03540190061030.

8. Doria AS, Moineddin R, Kellenberger CJ, Epelman M, Beyene J, Schuh S, et al. US or CT for diagnosis of appendicitis in children and adults? A meta-analysis Radiology. 2006;241:83-94.

9. Laméris W, van Randen A, van Es HW, van Heesewijk JP, van Ramshorst B, Bouma WH, et al. Imaging strategies for detection of urgent conditions in patients with acute abdominal pain: diagnostic accuracy study. BMJ. 2009;338:b2431. doi: 10.1136/bmj.b2431.

10. Carroll PJ, Gibson D, El-Faedy O, Dunne C, Coffey C, Hannigan A, et al. Surgeonperformed ultrasound at the bedside for the detection of appendicitis and gallstones: systematic review and meta-analysis. Am J Surg. 2013;205:102-8. doi: 10.1016/j.amjsurg.2012.02.017.

11. Burke LM, Bashir MR, Miller FH, Siegelman ES, Brown M, Alobaidy M, et al. Magnetic resonance imaging of acute appendicitis in pregnancy: a 5-year multiinstitutional study. Am J Obstet Gynecol. 2015;213:693.e1-6. doi: 10.1016/j.ajog.2015.07.026.

12. Golash V, Willson PD. Early laparoscopy as a routine procedure in the management of acute abdominal pain: a review of 1,320 patients. Surg Endosc. 2005;19:882-5. doi: 10.1007/s00464-004-8866-1.

13. Al-Temimi MH, Griffee M, Enniss TM, Preston R, Vargo D, Overton S, et al. When is death inevitable after emergency laparotomy? Analysis of the American College of Surgeons National Surgical Quality Improvement Program database. J Am Coll Surg. 2012;215:503-11. doi: 10.1016/j.jamcollsurg.2012.06.004.

14. Soreide K, Desserud KF. Emergency surgery in the elderly: the balance between function, frailty, fatality and futility. Scand J Trauma Resusc Emerg Med.2015;23:10. doi: 10.1186/s13049-015-0099-x.

15.Das K, Ozdogan M, Karateke F, Uzun AS, Sozen S, Ozdas S. Comparison of APACHE II, P-POSSUM and SAPS II scoring systems in patients underwent planned laparotomies due to secondary peritonitis. Ann Ital Chir. 2014;85:16-21.

16. Vincent JL, Moreno R, Takala J, Willatts S, De Mendonça A, Bruining $\mathrm{H}$, et al. The SOFA (Sepsis-related Organ Failure Assessment) score to describe organ dysfunction/failure. On behalf of the Working Group on Sepsis-Related Problems of the European Society of Intensive Care Medicine. Intensive Care Med. 1996;22:70710. doi: 10.1007/BF01709751.

17. Vincent JL, de Mendonça A, Cantraine F, Moreno R, Takala J, Suter PM, et al. Use of the SOFA score to assess the incidence of organ dysfunction/failure in intensive care units: results of a multicenter, prospective study. Working group on "sepsis-related problems" of the European Society of Intensive Care Medicine. Crit Care Med. 1998;26:1793-800.

doi: 10.1097/00003246-199811000-00016.

18. Coccolini F, Tranà $\mathrm{C}$, Sartelli $\mathrm{M}$, Catena F, Di Saverio S, Manfredi R, et al. Laparoscopic management of intra-abdominal infections: systematic review of the literature. World $J$ Gastrointest Surg. 2015;7:160-9. doi: 10.4240/wjgs.v7.i8.160.

19. Burch JM, Ortiz VB, Richardson RJ, Martin RR, Mattox KL, Jordan GL., Jr Abbreviated laparotomy and planned reoperation for critically injured patients. Ann Surg. 1992;215:476-83. doi: 10.1097/00000658-199205000-00010.

20. Demetriades D, Salim A. Management of the open abdomen. Surg Clin North Am. 2014;94:131-53. doi: 10.1016/j.suc.2013.10.010.

21. Montravers P, Augustin P, Grall N, Desmard M, Allou N, Marmuse JP, et al. Characteristics and outcomes of anti-infective de-escalation during health care-associated intra-abdominal infections. Crit Care. 2016;20:83. doi: 10.1186/s 13054-0161267-8.

22. Jeon HG, Ju HU, Kim GY, Jeong J, Kim MH, Jun JB. Bacteriology and changes in antibiotic susceptibility in adults with community-acquired perforated appendicitis. PLoS One. 2014;9:e111144. doi: 10.1371/journal.pone.0111144.

23. Rhodes A, Evans LE, Alhazzani W, Levy MM, Antonelli M, Ferrer R, et al. Surviving sepsis campaign: international guidelines for management of sepsis and septic shock: 2016. Intensive Care Med. 2017 Jan 18. 